\title{
NECROLOGICO
}

\section{ATIVIDADES MALACOLOGICAS DE HUGO DE SOUZA LOPES}

\author{
Arnaldo C. dos S. Coelho ${ }^{1}$ \\ Célia Neli Ricci ${ }^{1}$
}

Nascido a 5 de janeiro de 1909 no Rio de Janeiro, faleceu à 10 de maio de 1991, na mesma cidade.

Concluiu em 1933, o curso de Medicina Veterinária, na atual Universidade Federal Rural do Rio de Janeiro, onde foi Assistente do Professor Lauro Travassos (1934-1938), posteriormente Professor Catedrático de Zoologia Médica e Parasitologia (1938-1964) e Professor Emérito. Atuou também como Assistente do Professor Lauro Travassos, no curso de História Natural da antiga Universidade do Distrito Federal (1935-1937).

No Instituto Oswaldo Cruz foi estagiário de 1931-1933 e pesquisador, sem remuneração (1938-1949), quando foi contratado efetivo até 1970, ocasião em que, juntamente com outros pesquisadores, por Ato Institucional, foram aposentados e suspensos os seus direitos políticos. Retorna como Pesquisador Titular em 1986, exercendo as atividades até o falecimento.

De 1933-1937, trabalhou no Instituto de Biologia Vegetal, Ministério da Agricultura, juntamente com os renomados entomologistas Angelo Moreira da Costa Lima e Frei Thomaz Borgmeier.

A partir de 1977, prestou eficiente colaboração à Universidade Santa Úrsula, dedicando-se ao ensino e pesquisa de Entomologia.

$\mathrm{O}$ reconhecimento de seus méritos como pesquisador e professor o levaram a Membro Titular da Academia Brasileira de Ciências, em 1952.

Já na condição de eminente zoólogo, consagrado entomologista de elevado conceito nacional e internacional, como especialista em dípteros, interessou-se pelos moluscos, inicialmente apenas como preenchimento do tempo disponível durante um Curso de Entomologia que ministrava em Salvador, em 1949, quando tinha oportunidade de percorrer as praias coletando junto com os que "mariscavam" na baixa-mar, e com os quais trocava os exemplares menos comuns - material que constituiu o núcleo inicial da coleção que passou a acondicionar em caixinhas de cartolina, por espécie e, em caixas maiores, de papelão e madeira, projetadas e construidas por ele mesmo, contendo as

1) Museu Nacional do Rio de Janeiro, Universidade Federal do Rio de Janeiro, Quinta da Boa Vista, 20940-040 Rio de Janeiro, Rio de Janeiro, Brasil. 
famílias dispostas em ordem sistemática, num gabinete sobre a garagem de sua casa no Grajaú, onde na década de 50, Maury Pinto de Oliveira, Eliézer de Carvalho Rios e Arnaldo Campos dos Santos Coelho tiveram agradável convívio e ilustrativo aprendizado.

Ampliou grandemente a coleção, por meio de constante coleta e intensa permuta com colecionadores estrangeiros, reuniu bibliografia especializada, por compra, doação e troca de conchas.

Manteve com João de Paiva Carvalho, do Intituto Oceanográfico de São Paulo e Paulo de Sá Cardoso, colecionador amador, de Maceió, extensa correspondência e a grande motivação pelo conhecimento dos gastrópodes marinhos de pequenas dimensões.

Mais tarde, a valiosa coleção e a excelente biblioteca, embora permanece como de sua propriedade, foram acomodadas em dependências do Instituto Oswaldo Cruz, onde sob sua orientação tiveram formação e desenvolveram estudos: Pedro Jurberg, Orlando Guerra Jr., Hugo Edison Barbosa de Rezende, Pedro Domingues Lanzieri e José Luiz de Barros Araújo.

Em 1970, com o deplorável movimento desencadeado pela Direção do Instituto Oswaldo Cruz, Hugo de Souza Lopes dotado de personalidade plena de compreensão e desprendimento, em atitude consciente e decisiva doou a coleção e a bibliografia ao Museu Nacional, instituição com a qual sempre manteve contato, prestando inestimável e inesquecível colaboração.

Em 1989, por ocasião dos oitenta anos de idade do Professor Hugo de Souza Lopes, o Instituto Oswaldo Cruz, em suplemento especial comemorativo, reuniu 92 artigos de seus discípulos, colegas, amigos-brasileiros e estrangeiros, onde foi apresentada, além da vida profissional, a lista de suas publicações Mem. Inst. Oswaldo Cruz 84 (Supl. 4): XV + 568p.

Analisando as atividades desenvolvidas por Hugo de Souza Lopes no correr desses 60 anos, com relação ao interesse malacológico, consideramos as seguintes fases:

\section{Do entomologista, especialista em dípteros que estudou a relação com os moluscos}

LOPES, H.S. 1938. Sur une espéce du genre Charadrella Wulp. (Diptera, Anthomyidae) trouvée au Breésil et vivant aux dépens de Bulimus taunaysi Fér. (Mollusca, Pulmonata). C. R. Soc. Biol. 128: 926-928.

Como o próprio título sugere, descreveu a espécie nova com base em larvas encontradas em conchas de animais mortos nas ruinas do Grajaú, Rio de Janeiro.

LOPES, H.S. 1940. Contribuição ao conhecimento do gênero Udamopyga Hall e de outros Sarcophagídeos que vivem em molluscos no Brasil (Diptera). Rev. Ent., Rio de Janeiro, 11 (3): 924-954.

Apresentou resenha bibliográfica universal, em que adota a expressão "Dípteros Parasitóides" para os predadores que depositam os ovos, cujas larvas 
se localizam em órgãos de importância vital, aproveitando para sua alimentação apenas uma pequena parte do organismo a que se associam; com os dípteros parasitóides se instalam vários outros dípteros que aproveitam o organismo lesado, com sua defesa diminuida e dele se alimentam.

LOPES, H.S. 1966. Sobre Malacophagomyia g.n. (Díptera, Sarcophagidae) cujas larvas vivem em cadáveres de Gastropoda (Mollusca). Rev. Brasil. Biol., Rio de Janeiro, 26 (3): 315-321.

Tratou da descrição do novo gênero, em que a espécie tipo Sarcophaga filamenta Dodge, 1963 é redescrita com base em material obtido de larvas encontradas em exemplares mortos de gastrópodes - Solaropsis brasiliana (Deshayes) (RJ, Rio, Campo Grande): Pomacea sp. (Pará, Belém, Pq. Museu Paraense) e Pomacea bridgesi (Reeve) (Bolívia, Santa Cruz de La Sierra).

LOPES, H.S. 1969. Neotropical Sarcophagidae, reared from Gastropoda by Dr.

W. Weyrauch (Diptera). Studia Ent., Petrópolis, 12 (1/4): 133-60.

Descreveu gêneros novos e espécies novas de larvas criadas pelo Dr. Weyrauch de gastrópodes bulimulídeos e ampularídeos coletados no Peru, Argentina e Brasil.

LOPES, H.S. 1973. Collecting and rearing Sarcophagid flies (Diptera) in Brazil

during forty years. An. Acad. Brasil. Ciênc., Rio de Janeiro, 45 (2): 279-291.

Em que comentou as atividades no período expondo técnicas de trabalho e de coleta, resumindo o conteúdo dos artigos que trataram da relação dípteros versus moluscos.

\section{Sobre os moluscos em geral}

LOPES, H.S. \& M. ALVARENGA. 1957. Contribuição ao conhecimento dos moluscos de Fernando de Noronha-Brasil. Bol. Inst. Oceanog., São Paulo, 6 (1/2) (1955): 157-196.

Com base em material coletado por M. Alvarenga, em duas viagens, e no enviado por um de seus contatos na ilha, são comentadas as espécies de bivalves marinhos e de gastrópodes marinhos e terrestres, além de na introdução tecerem comentários sobre as referências bibliográficas existentes (todas do século XIX) e sobre a distribuição geográfica das espécies.

LOPES, H.S. \& A.C.S. COELHO. 1960. Contribuição para o Inventário Crítico da Zoologia do Brasil, 1500-1960. Mollusca. I Congresso Brasileiro de Zoologia, Rio de Janeiro, Comunicação, sem resumo publicado.

Em que foram levantados e comentados obras e periódicos existentes no Brasil; especialistas e colecionadores; levantamento de material-tipo e outros dados sobre as coleções.

LOPES, H.S. 1957. Relação dos moluscos coletados na excursão às zonas das

Estradas de Ferro Noroeste do Brasil e Brasil-Bolívia, nos Estados de São Paulo e de Mato Grosso, Brasil e Bolívia. Publ. Avul. Mus. Nac., Rio de Janeiro, 20: 43-44.

Em que esclareceu serem quatro espécies de Pomacea identificadas por 
T. Pain, relacionou seis espécies de gastrópodes terrestres e uma de bivalve de água doce.

\section{Sobre gastrópodes em geral}

CINTRA, H. \& H.S. LOPES. 1952. Sur la forme et quelques caracteristiques mathematiques des coquilles des gastéropodes (Mollusca). Rev. Brasil. Biol., Rio de Janeiro, 12 (2): 185-200.

Estudaram a forma do desenvolvimento da sutura das conchas de gastrópodes, realizando medidas sobre exemplares de espécies marinhas (Littorina angulifera, L. nebulosa flava e Hastula cinerea) e de espécies terrestres (Strophocheilus oblongus e Obeliscus obeliscus).

Concluiram que nem sempre uma espécie é caracterizada por uma espiral determinada, mas o tipo da espiral é constante para as espécies estudadas. A espiral mais frequentemente encontrada foi a logarítimica.

Admitiram, esquematicamente, que a concha do gastrópode é formada pela rotação de uma curva plana fechada em torno de um eixo e que se mantém semelhante a si mesma quando se desloca em seu plano; esta curva por se manter semelhante a si mesma pode ser usada como um caráter específico.

Para as medidas criaram pequeno aparelho figurado no artigo.

\section{Sobre gastrópode terrestre}

LOPES, H.S. 1955. Sobre Entodina lundi (Mörch, 1871) (Mollusca, Pulmonata, Systrophiidae). Rev. Brasil. Biol., Rio de Janeiro, 15 (3): 243-246.

Com base em material obtido por Angelo B. M. Machado em grutas calcárias de Vespasiano, próximo à Lagoa Santa, Minas Gerais, fez comentários sobre as espécies em geral e principalmente sobre as espécies de Entodina registrads para o Brasil.

Para a espécie descrita por Mörch, em homenagem a P.W. Lund, o naturalista que vivera na região, apresentou excelente caracterização e detalhadas ilustrações.

\section{Sobre os gastrópodes marinhos de pequenas dimensões}

LOPES, H.S. 1958. Sobre Turbonilla (Pyrgiscus) dispar Pilsbry, 1897 (Gastropoda, Pyramidellidae). Rev. Brasil. Biol., Rio de Janeiro, 18 (1): 17-21.

Primeiro artigo da série, em que tratou o material obtido de conteúdo estomacal de "estrela-do-mar", enviado por E. de Carvalho Rios, em que evidenciou a variação de forma, ornamentação e do número de costelas.

LOPES, H.S. \& P.S. CARDOSO. 1958. Sobre um novo gastrópodo brasileiro do gênero Solariella Wood, 1842 (Trochidae). Rev. Brasil. Biol., Rio de Janeiro, 18 (1): 59-64. 
Este artigo ressaltou o contato de H.S. Lopes com dois interessados no assunto, o colaborador Paulo de Sá Cardoso (o mais antigo colecionador brasileiro de moluscos - 1939 - Maceió, Alagoas) e o homenageado com o nome da espécie, João de Paiva Carvalho (do Instituto Oceonográfico de São Paulo com quem trocavam material e informaçóes). Aproveitaram para apresentar o levantamento das espécies de Solariella (s.s.) assinaladas para o Atlântico Ocidental.

LOPES, H.S. \& A.C.S. COELHO. 1961. Microgastrópodes marinhos da Bahia.

II Congresso Brasileiro de Zoologia, Porto Alegre, Comunicação, sem resumo publicado.

Trataram das conchas desses gastrópodes, obtidos exclusivamente na "linha-do-deixa", junto ao Farol de Itapuã, Salvador, Bahia. Evidenciaram as inúmeras trocas de material e informações realizadas com João de Paiva Carvalho e Paulo de Sá Cardoso.

Foram apresentados "slides" das ilustrações a bico-de-pena, realizadas por desenhistas que também interessaram-se pelo projeto.

LOPES, H.S.; A.C.S. COELHO \& P.S. CARDOSO. 1965. Uma nova espécie brasileira do gênero Mitrella Risso, 1826 (Gastropoda, Columbellidae). Rev.

Brasil. Biol., Rio de Janeiro, 25 (1): 21-24.

Primeira contribuição sobre a família, cujo estudo foi projetado também em termos monográficos, entretanto, analisada a impossibilidade de conclusão rápida e mesmo o da publicação de trabalho volumoso, foi dada ao conhecimento a caracterização e ilustração de Mitrella albovitata.

LOPES, H.S.; A.C.S. COELHO \& P.S. CARDOSO. 1966. Contribuições ao conhecimento dos gastrópodes marinhos do Brasil. I. Família Rissoidae (Mesogastropoda - Rissoacea). Bol. Mus. Nac., N.S., Zool., Rio de Janeiro, 254: 1-11.

Estudo de oito representantes da família com as devidas caracterizações e detalhadas ilustrações a bico-de-pena.

LOPES, H.S.; A.C.S. COELHO \& P.S. CARDOSO. 1971. Considerações sobre a família Columbellidae no Brasil (Mollusca: Gastropoda). Arq. Mus. Nac., Rio de Janeiro, 54: 29-30.

Em que considerando os trabalhos de MARCUS \& MARCUS (1962 e 1964) dedicados ao estudo das partes moles, como excelentes contribuições, foi possível o estabelecimento do arranjo de cinco grupos de espécies do material brasileiro. Tal estudo foi apresentado no III Congresso Brasileiro de Zoologia, Rio de Janeiro, 14-20-VII-1968.

\section{Sobre os gastrópodes de água doce dos Ampulariídeos}

LOPES, H.S. 1955. Sobre duas espécies do gênero Pomacea Perry, com um estudo da genitália em ambos os sexos (Mesogastropoda, Architaeniglossa, Mollusca). Rev. Brasil. Biol., Rio de Janeiro, 15 (2): 203-210.

LOPES, H.S. 1956. Sobre Pomacea lineata (Spix, 1827) (Mesogastropoda, 
Architaenioglossa, Mollusca). Rev. Brasil. Biol., Rio de Janeiro, 16 (3): 375-380.

LOPES, H.S. 1956. Sobre Pomacea canaliculata (Lamarck, 1822) (Mesogastropoda, Architaenioglossa, Mollusca). Rev. Brasil. Biol., Rio de Janeiro, 16 (4): 535-542.

LOPES, H.S. 1957. Observações sobre as espécies do gênero Pomacea Perry. In: IX Reunião Anual da Sociedade Brasileira para o Progresso da Ciência, 8-13-VII-1957, Rio de Janeiro. Ciência e Cultura, São Paulo, 9 (4): 213.

Em que foram caracterizadas quatro espécies pelo exame detalhado das conchas e partes moles, bem como pelo estudo de várias gerações, com base na comparação do material capturado em natureza com o obtido em cativeiro de ambos os sexos.

Baseou-se nas identificações específicas de T. Pain, com o qual manteve grande contato e adotou a opinião de utilização de Pomacea Perry, 1810 ao invés de Ampullarius Montfort, 1810.

Para obter as partes moles do animal sem destruir a concha utilizou técnica própria, abrindo um orifício na última volta da concha, em oposição à abertura, fazendo passar pelo orifício uma agulha de costura, ligada a um fio de cobre delgado - a agulha dirigida ao longo da columela, surgindo a ponta na parte inferior da abertura; a extremidade livre do fio também introduzida na direção da margem superior da abertura, assim quando puxadas a agulha e a extremidade livre do fio, este correndo ao longo da columela desliga o músculo columelar de sua inserção e a lesma retirada inteira.

Essa técnica foi substituida por outra, após terem sido observadas as atividades do "Gavião Caramujeiro" Rostramus sociabilis sociabilis (Vieillot, 1817) no lago da Universidade Federal Rural do Rio de Janeiro, em que esse animal capturava exemplares de Pomacea spp. para sua alimentação e, fazendo penetrar o bico entre a face interna do opérculo e a região columelar destruindo o músculo columelar, desprendendo a lesma e ingerindo-a. Assim, elaborou uma haste metálica achatada, pontuda com o mesmo tamanho e curvatura do bico conseguindo repetir a operação do "gavião" com facilidade.

\section{Sobre bibliografia malacológica}

Publicou os pareceres: primeiro sobre "Moluscos do Brasil", de Eurico Santos, 1955 - comentando o conteúdo do décimo volume da série "Zoologia Brasílica", enaltecendo a obra de divulgação do conhecido autor; o segundo sobre "Tonnidae, Gastropoda, Prosobranchia", de R. Kilias, 1962 - monografia integrante da obra seriada Das Tierreich, cuja publicação havia sido interrompida, com a segunda guerra mundial e retomada em 1958. - Respectivamente em 1956 e 1962, na Rev. Brasil. Biol., Rio de Janeiro, 16 (2): 25822 (3): 332.

Em 1989, por ocasião da referida publicação do suplemento das Memórias, os malacologistas homenagearam-no com 15 artigos sobre/ou relacionados aos moluscos. 
Permitiu assim o destino, que Hugo de Souza Lopes recebesse, ainda em vida, os aplausos e reconhecimento pela atuação de verdadeiro naturalista, na condição de Grande Mestre que, no ensino e na pesquisa, sabia descer ao nível dos principiantes elevando-os ao próprio nível.

Recebido em 30.XII.1991; aceito em 25.XI.1993. 